\section{FRACTURE OF THE FEMUR INTO AN ACTIVELY TUBERCULOUS KNEE-JOINT}

\section{WITH HEALING OF THE FRACTURE}

\section{CHARLES A. PARKER, M.D.} CHICAGO

The following case recently under the care of Dr. Ridlon and myself appears to be of sufficient clinical importance to merit recording:

History.-The patient is a man aged 26 , who has suffered more or less continuously from trouble in his right knee since he was 6 years old. It had been pronounced tuberculous. During the last two years he experienced a severe recrudescence of the trouble. In October, 1912, he fell on the knee and a diagnosis of fracture was made by the attending surgeon, and various treatments of the fracture and of the joint were carried out.

He came to our office March 18, 1913, wearing a cast and with a discharging sinus over the inner aspect of the knee. The knee was straight, swollen and had slight motion in flexion. There was more lateral motion and the joint was very sensitive. A roentgenogram was taken and a cast applied.

Figure 1 shows the type and extent of the fracture as well as the amount of destruction in the joint.

It is a typical supracondylar fracture of the femur with a vertical fracture through the external condyle down into the joint, and an oblique fracture extending 2 or 3 inches up into the shaft of the femur.

Whether or not there were more vertical clefts originally present, it is impossible to say from the picture. The picture shows some evidence of callus formation on either side of the femur overlapping the transverse fracture and a large posterior shadow that looks like callus, but without definite outline. The joint surfaces show a typical tuberculous picture. On account of the extreme tenderness of the part no attempt was made to determine the character of the union of the fracture; but the character of the joint and the age

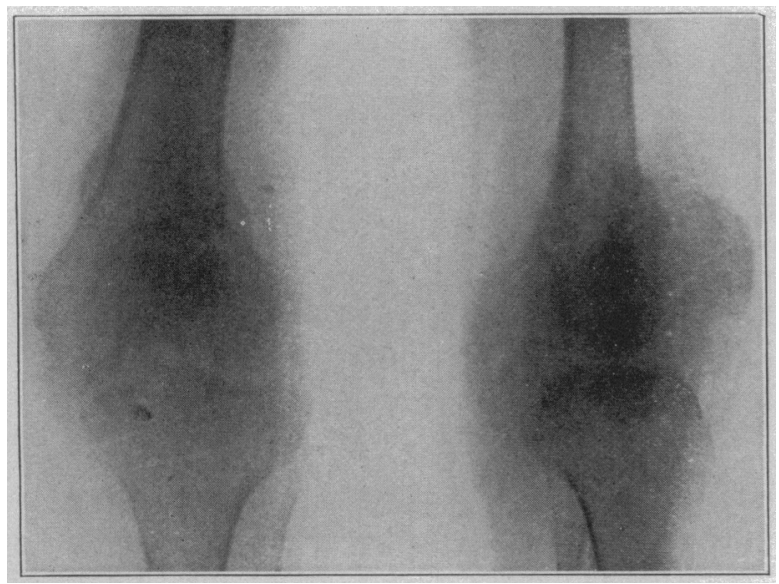

Fig. 1.- Roentgenogram showing fracture of the lower end of the femur extending into the actively tuberculous joint.

of the patient, together with his appearance of suffering from chronic sepsis, influenced us to suggest amputation of the thigh as the best solution of the problem. This was agreed on and the thigh was amputated just above the lower third, April 3, 1913. The operation was performed at the Presbyterian Hospital. A large tuberculous abscess was opened when the muscles of the front of the thigh were cut, four or five inches above the joint. Its walls were removed together with considerable sound tissue and the whole surface sponged with tincture of iodin and the wound entirely closed, a small gutta-percha drain extending into the deeper parts through a stab wound in the posterior flap. Healing was prompt and uneventful.

The Specimen.-The soft tissues were removed from the specimen and the bone examined. Incidentally it may be noted that the region back of the joint, that is so definitely defined in the roentgenogram and appears as a deposit of lime-salts, showed nothing abnormal to the naked eye, although it was believed that a slight grating on the knife could be detected on scraping the cut surface. It consisted mostly of the popliteal fat in which there were no doubt calcareous elements, but not arranged so as to form any definite calcareous structure. The callus seen on either side of the femur in the roentgenogram was very slight and soft, but the union of all the parts of the lower end of the femur was so firm that no movement whatever could be detected in them on testing the strength in our hands; in fact, there was a definite firm bony union with good position and in the presence of an actively tuberculous joint (Fig. 2) A histologic study of the tissue taken from the region of the posterior shadow failed to show any lime deposits or other conditions that might produce such a shadow. An excess of lime-salt may have been present, but not in a form recognizable by histologic methods.

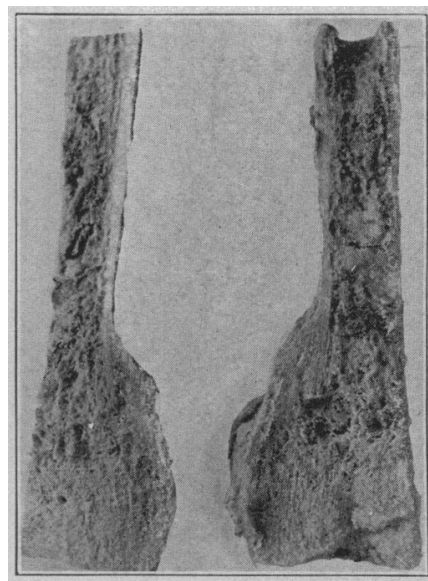

Fig. 2.- Section of lower end of femur in Figure 1, showing union of fragments.
Of course one instance is hardly sufficient on which to base a rule of practice, but it is the best evidence of what has occurred and in so much may influence us as to what may occur again. In other words, a fracture into an actively tuberculous joint can heal in a satisfactory manner, leaving only the original joint trouble for treatment according to the usual methods pursued in such troubles. Possibly another case may not progress so favorably as this case as far as the fracture is concerned, but this case certainly justifies us in expecting the bony union and a final heaing of the joint in those cases in which the conservative healing of the joint is ordinarily indicated.

Another fact that should be emphasieed in this connection is the presence of a shadow strongly suggestive of callus in a region in which operation demonstrates no callus to be present; or, in other words, what appears to be an insurmountable obstruction to flexion is in reality no obstruction at all.

7 West Madison Street.

The Value of a Pleasant Hospital Exterior.-In the description of a hospital a writer in Country Life says: "It is sometimes said that it is wrong to expend any money on the outside of a hospital, and that every halfpenny should be devoted to operating-tables and the like. This is surely a prejudiced idea. No building of a public sort should present a repellent front to the passerby; least of all, a hospital which owes a smiling welcome to those who approach it with some sinking of heart. There are hospitals enough which suggest by their door faces, 'All hope abandon ye who enter here.' We need' not be psychologists to recognize that none more than the sick need the subtle aid, not only of a happy environment within, but of the cheering welcome of an exterior that is homelike rather than 'institutional.'" 